\title{
EFFECTS OF SELECTIVE COOLING OF SPECIFIC HUMAN BODY SURFACE AREAS ON SUBJECTIVE ASSESSMENT OF THERMAL COMFORT IN HOT CONDITIONS
}

Anna PRZEWODZKA, Anna CZERWIŃSKA

Military Institute of Aviation Medicine, Warsaw, Poland

Source of support: This study was carried out as part of the research project entitled: "Rules of the protection of flight crew from the adverse effects of heat stress and of the improvement of procedures for the qualification of candidates (flight crew) to perform their duties in hot weather zones (objective indicators)". The project was financed by the Ministry of National Defense.

Author's address: A. Przewodzka, Military Institute of Aviation Medicine, Krasińskiego 54/56 Street, 01-755 Warsaw, Poland, e-mail:aprzewo2@wiml.waw.pl

Introduction: The aim of the study was to determine whether changing the location of a selectively cooled body surface area in hot conditions, using a thermal stimulus of the same temperature and the same area and time of cooling, has an effect the on subjective assessment of thermal comfort.

Methods: The experiment was participated by 10 healthy men who were not accustomed to high temperatures. Conducting a unit study included: a 30 minute period of adaptation to the thermoneutral conditions followed by 45 minutes of exposure to hot conditions $\left(40^{\circ} \mathrm{C}\right)$, including 30 minutes of an uncooled period and 15 minutes of selective cooling of the neck (series I) or sternum (series II) (stimulus temperature: $10-12^{\circ} \mathrm{C}$ ). The thermal state of the body was evaluated three times using the Bedford test: in the 30th minute of adaptation to the thermoneutral conditions, in the 30th minute of exposure to high temperature and in the 15th minute of cooling in hot conditions. Assessment of thermal sensations in relation to the selectively cooled area (neck, sternum) and the assessment of thermal comfort in relation to the whole body were analyzed.

Figures: 4 • References: 21 • Full-text PDF: http://www.pjambp.com • Copyright @ 2018 Polish Aviation Medicine Society, ul. Krasińskiego 54/56, 01-755 Warsaw, license WIML • Indexation: Index Copernicus, Polish Ministry of Science and Higher Education 
Results: As a result of 15 minutes of cooling, a significant decrease in skin temperature in the neck region was obtained at the level of $\triangle \mathrm{TskNECK}=-2.2 \pm 0.1^{\circ} \mathrm{C}$ and sternum $\triangle \mathrm{TskSTERNUM}$ $=-1.8 \pm 0.1^{\circ} \mathrm{C}$. A positive effect on the subjective assessment of thermal comfort in the whole body was observed in $70 \%$ of the participants who cooled the neck area and in $40 \%$ of the participants who cooled the sternum area. The positive effect on thermal sensations caused by cooling the neck area was observed in $80 \%$ of the participants, and the positive effect of cooling the sternum area was observed in $50 \%$ of the participants.

Discussion: Selective cooling of the neck or sternum area in hot conditions positively improves thermal sensations. The local sensitivity of the skin to low temperatures is greater in the area of the neck than in the sternum. The improvement of subjective assessment of thermal comfort in relation to the whole body was greater after the application of selective cooling on the neck surface than on the sternum. Local cooling of the skin surface with a low-temperature stimulus $\left(10-12^{\circ} \mathrm{C}\right)$ in hot conditions $\left(40^{\circ} \mathrm{C}\right)$ does not cause the feeling of thermal discomfort.

Keywords: selective cooling, thermal comfort, thermal sensations, psychophysical state, bedford scale

\section{INTRODUCTION}

The thermal conditions of the environment in which military tasks are carried out (cockpit interior, hot climate zone), as well as using protective clothing (e.g. g-suits, helmets) adversely affect physiological processes and cognitive functions of a soldier's organism. The combined effect of these factors leads to severe thermal stress, overheating of the body, which can be seen both through subjective assessment and in relation to physiological reactions (increase in skin temperature Tsk, core body temperature Tc or heartbeat rate $\mathrm{HR})[10,12]$. In high temperature conditions (above $27^{\circ} \mathrm{C}$ ), the learning ability and processes of memorizing and logical reasoning deteriorate, the level of concentration, perception and alertness (expressed as an increase in the number of errors) and the efficiency of problem solving also decreases, e.g. in mathematical calculations $[5,14,16]$. In addition, it has been shown that the human thermoregulatory system and sleep mechanisms are also strongly interrelated. If the ambient temperature is too high, it can significantly reduce the quality of sleep during the night, which has been confirmed by numerous tests. Poor sleep quality deteriorates motor coordination, cognitive performance, and affects brain functions related to risktaking and cognition while awake $[8,13,18,19]$. As heat load indicators (Tsk, Tc, HR) worsen, so do the cognitive processes, as well as the subjective assessment of temperature and burden of physical work. In view of the existing threats to maintaining thermal comfort in a thermal balance state, it is extremely important to regulate the temperature of the body [14].
Thermal stimulation is perceived by the body as comfortable when the body temperature is maintained within the limits of physiological norms. However, the feeling of discomfort occurs when the internal thermal conditions deteriorate. Information about external thermal conditions reaches the body through signals transmitted from the skin's thermoreceptors, which are unevenly distributed on the body. Depending on the body's thermal state, every flow of stimuli in sensory processes from the skin surface to the central nervous system is described either as "comfortable" or "uncomfortable". It is interesting that the degree of intensity of these changes is not the same in all areas on the body. Research has shown that the local thermal sensations and the thermal comfort for the whole body are differentiated depending on the location of the thermal stimulus on the skin. For example, Arens et al. observed that the head and neck area is more sensitive compared to less sensitive limbs (shoulders, legs) or moderately sensitive other areas of the body (torso, back). In the experiment conducted by the Nakamura team, the participants exposed to hot conditions assessed cooling in the facial area as more effective than in the abdomen and thighs $[1,15]$. Thermal sensations received from the back, chest and pelvic area have a stronger effect on the change in comfort for the whole body than thermal sensations received from the palm and foot surfaces $[2,7]$. Hensel et al. observed that cooling one's hands in a warm environment invokes a feeling of cold in that particular part of the body, but the overall thermal sensation changes 
only slightly from "pleasantly warm" to "pleasant" [7]. Similarly, other studies have shown that cooling of limbs (hands, feet) has less effect on thermal comfort than torso areas, and that cooling of face and neck in hot conditions is the most comfortable $[14,15,21]$.

Thermal comfort is a state of satisfaction of the body with the surrounding thermal environment, so it is not described as either cold or warm. In addition, this condition is not associated with a specific temperature value. The opinion and assessment of people in different environments constitute the basis for information on their state of thermal comfort. Subjective evaluation of the state of thermal comfort in relation to the whole body is characterized by intra-individual variability (everyone can perceive the surrounding thermal conditions in a different way). It depends on the personality, level of daily activity, degree of insulation of clothing and physical factors characterizing the environment. When cooling a specific area on the body, general well-being and subjective assessment of the state of comfort are improved. For example, using a PCM cooling vest improves the thermal sensations felt by the body and the skin moisture level assessment in hot $\left(34^{\circ} \mathrm{C}\right)$ conditions [6]. We have also confirmed this in our own experimental studies. It is particularly beneficial to maintain thermal comfort in relation to the head surface. Studies have confirmed that head cooling is an effective way to reduce the level of thermal stress in the awake state and is most likely the result of significant heat loss by the head [4]. The Pallubinsky team reported that cooling only the face or face and armpits is also an effective way to improve thermal sensations and thermal comfort in a warm environment. External interference in the process of heat loss from this part of the body not only improves the subjective assessment of the thermal state, but also changes the assessment of the degree of inconvenience the performed work (fatigue level) [17]. Moreover, cooling the surface of the head area has a positive effect on heat load indicators, e.g. it reduces the heartbeat rate. Psychomotor performance, information processing, awareness and focus can also be improved, which often contributes to the decrease in the number of mistakes made. To sum up, the reduction of thermal stress influences the assessment of thermal comfort in a positive way, which may translate into the reduction of perceived fatigue and limitation of performance decrease $[7,14]$. Extending the body's tolerance to high temperature by using a low temperature thermal stimulus can have a positive impact on the safety threshold of the tasks performed, especially in difficult and unfavorable environmental conditions. Therefore, the aim of the Military Institute of Aviation Medicine study was to determine to what extent the change of location of selective body surface cooling (neck and sternum) using the same thermal stimulus $\left(10-12^{\circ} \mathrm{C}\right)$ on the same area $\left(100 \mathrm{~cm}^{2}\right)$ and same duration (15 $\mathrm{min}$ ) in hot conditions $\left(40^{\circ} \mathrm{C}\right)$ differentiates the subjective assessment of thermal comfort.

\section{MATERIAL AND METHODS}

\section{Participants in experimental research}

The experimental group consisted of 10 healthy young men $(n=10)$ aged $24.5 \pm 0.5$ years with the following anthropometric parameters: body weight $67.9 \pm 1.8 \mathrm{~kg}$, body height $1.73 \pm 0.02 \mathrm{~m}, \mathrm{BMl}$ : $22.72 \pm 1.6 \mathrm{~kg} / \mathrm{m}^{2}$ ) not previously acclimated to high temperatures. All participants were admitted to the study by an occupational physician. In order to minimize the level of situational stress, participants were familiarized with the climate chamber exposure procedure and its physiological consequences. During the day preceding the experiment, the participants were obligated to maintain a hygienic lifestyle (application of dietary recommendations, not consuming alcohol and intoxicants). Before proceeding further, each of them agreed in writing to participate in the experiment.

\section{Selection of the method of selective cooling}

The selection of material and methods of selective cooling was based on the analysis of literature data and the results of own experiments. As a selective cooling method, "cooling pads" (cooling surface $-100 \mathrm{~cm}^{2}$ ) were used, which were filled with non-toxic propylene glycol in gel form and a temperature of $10-12^{\circ} \mathrm{C}$. The refrigerant was sealed in a welded plastic bag, which made for a sturdy and resistant container. This type of compress did not cause a feeling of humidity (as in the case of, for example, melting ice).

The "cooling pad" used has many beneficial properties: 1) the elasticity of the material ensures that, even after freezing, the "pad" adheres well to the body surface without sticking to the skin; 2) a non-toxic coolant (propylene glycol) with a very high specific heat of $3,38 \mathrm{~J} /(\mathrm{gK})$. The favorable heat transfer coefficient ensures that the heat is properly transferred from the surface of the body; 3 ) it does not constitute an additional load; 4) it does not limit the comfort of movement; 5) it is economical due to the possibility of repeated use 
(during operation there are no irreversible chemical changes in the gel, the cooling effect is always the same). However, the "pad" must be externally cooled in the refrigerator before use. In addition, they do not keep their temperature for long and they have a limited time of operation.

\section{Organization of research}

The experiment was conducted under an identical and reproducible environmental conditions, in autumn (September to October) at the Department of Aviation Physiology of the Military Institute of Aviation Medicine (WIML) in Warsaw. The research project was approved by the WIML Human Research Ethics Committee. Each unit test was started at the same time in order to minimize differences resulting from daily rhythm as much as possible. Each participant engaged in the experiment twice, with a 24-hour break between successive exposures.

Two series of unit tests were carried out. The "cooling pad" was applied to the skin surface in series I - in the neck area, in series II - in the sternum area. Each time, before application, the "pad" was cooled to $10-12^{\circ} \mathrm{C}$ and then, after drying with a cotton towel, it was fixed to a specific place (sternum or neck) using flexible tapes.

\section{Physical characteristics of the environment}

Both series I and II of the experiment were conducted in simulated conditions of a hot climate chamber of the Military Institute of Aero-medical Sciences. In both series constant and reproducible conditions of the chamber interior were maintained: air temperature $\mathrm{Ta}=40 \pm 0.5^{\circ} \mathrm{C}$, relative humidity $\mathrm{RH}=30 \pm 1 \%$, air flow velocity $\mathrm{V}=1 \mathrm{~m} / \mathrm{s}$.

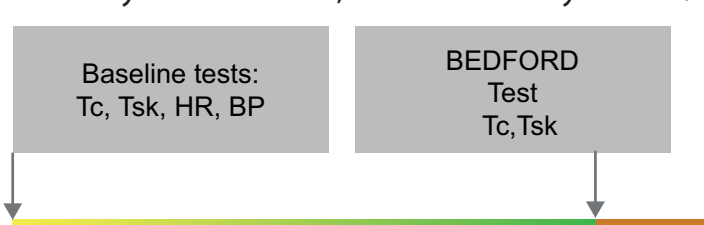

\section{Conduct of the unit study}

All participants of the study started the experiment after a standard breakfast, proper placement of physiological indicators and baseline measurements (internal body temperature Tc, skin temperature of TskNECK and TskSTERNUM, heart rate $\mathrm{HR}$, blood pressure BP). During the experiment, the participants were sitting, wore cotton shirts, shorts and sports shoes. Conducting a unit test included: 30 minutes adaptation to thermoneutral conditions ( $\left.\mathrm{Ta}=21.0 \pm 0.1^{\circ} \mathrm{C} ; \mathrm{RH}=30 \pm 1 \%\right)$ and 45 minutes of exposure to high temperature (climate chamber: $\mathrm{Ta}=40 \pm 0.5^{\circ} \mathrm{C} ; \mathrm{RH}=30 \pm 1 \%$ ). During the 30 minute stay in the climate chamber, a "cooling pad" with a temperature of $10-12^{\circ} \mathrm{C}$ was applied for a period of 15 minutes near the neck (series I) or sternum (series II) area.

During the experiment (series I and II) the examined person filled in the Bedford test three times in order to subjectively assess the thermal state of their body based on the 7-point Bedford Scale in the following stages: in thermoneutral conditions - in the 30th minute of adaptation, and in simulated hot conditions - in the 30th minute of adaptation to high temperature, and in the 15th minute of selective cooling of specific body surfaces (neck or sternum). At the same time, the parameters of internal body temperature Tc and skin temperature Tsk were measured. On the Bedford Scale, 1 means "too cold" and 7 "too hot". The values of 3 - "pleasantly cool", 4 - "pleasant" and 5 "pleasantly warm" are within the range of thermal comfort. Each time the participants assessed the thermal state of the whole body and the thermal sensation of the cooled area of the neck or sternum.

During exposure to simulated heat conditions the following physiological indicators were record-
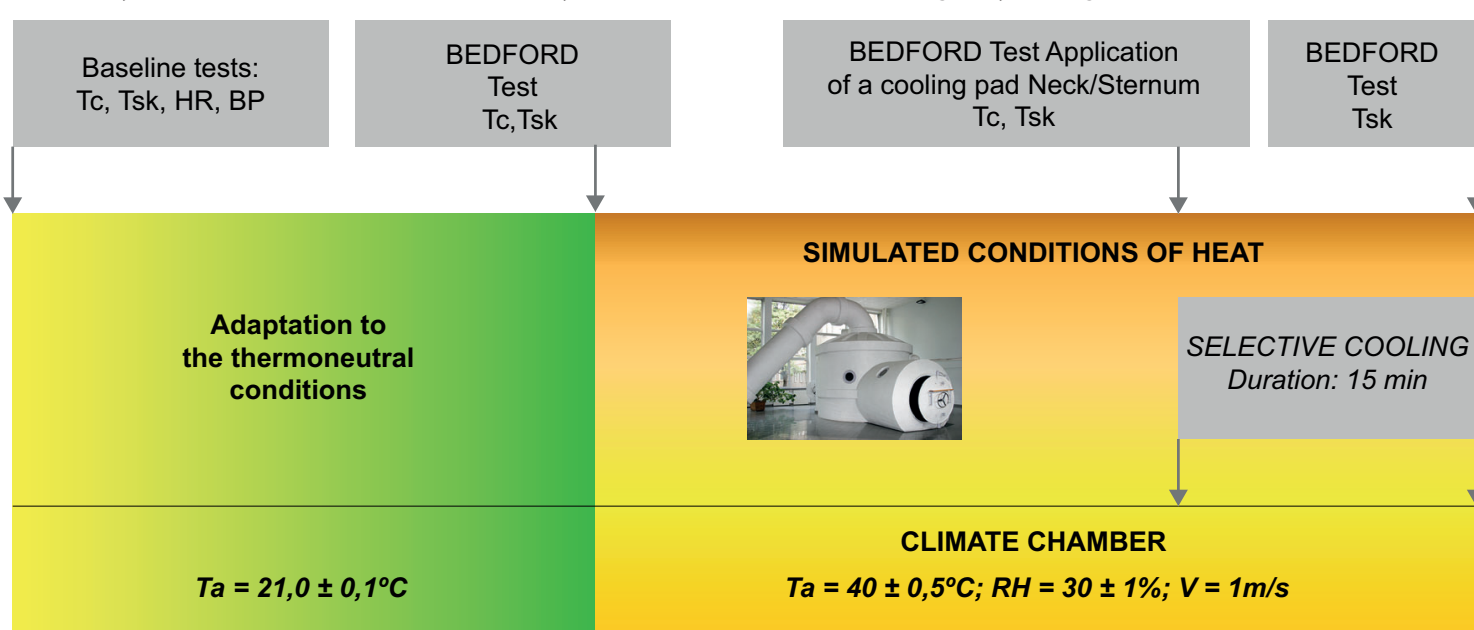

$30 \mathrm{~min}$.
SIMULATED CONDITIONS OF HEAT

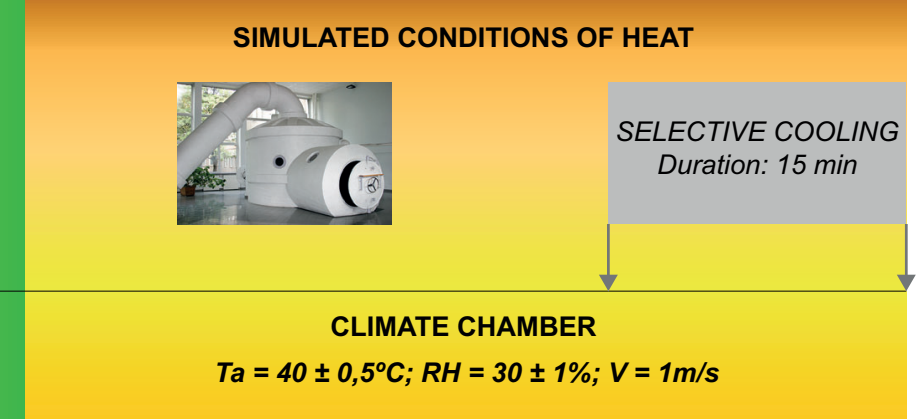

$45 \mathrm{~min}$.

Fig. 1. The course of the unit test under thermoneutral conditions and simulated hot climate chamber conditions. 
ed: body temperature (Tc) in the external ear canal using an electronic infrared thermometer, skin temperature (Tsk) using the Ellab thermocouple, a device equipped with humidity and temperature sensors, systolic and diastolic pressure (BP) measured using an electronic blood pressure monitor.

\section{Statistical analysis of results}

The values of parameters obtained as a result of cooling were related to the output values recorded at hot conditions before cooling. Changes in the analyzed psychological and physiological indicators were evaluated using the t-Student parametric test for dependent trials (assuming normality of distribution). The obtained data is presented as mean values \pm SD. The significance of the differences was assumed at the level of $p<0.05$. The StatSoft Polska Statistica 6.0 statistical package was used to analyze the results.

\section{RESULTS}

\section{Skin temperature}

Under thermoneutral conditions, the core body temperature was maintained at the mean value of $\mathrm{Tc}=37.1 \pm 0.1^{\circ} \mathrm{C}$, while the skin temperature reached the mean value of Tsk $=29.4 \pm 0.2^{\circ} \mathrm{C}$. During 30 minutes of exposure to hot temperature, the mean core body temperature value was $\mathrm{Tc}=$ $37.2 \pm 0.1^{\circ} \mathrm{C}$ and the mean skin temperature value for the neck was TskNECK $=34.1 \pm 0.1^{\circ} \mathrm{C}$ and was very close to the values obtained for TskSTERNUM $=34.3 \pm 0.2^{\circ} \mathrm{C}$. After applying selective body surface cooling (with the same temperature of 10$12^{\circ} \mathrm{C}$, same area of $100 \mathrm{~cm}^{2}$ and duration of $15 \mathrm{~min}$ utes) during exposure to high temperature $\left(40^{\circ} \mathrm{C}\right)$ different levels of skin cooling were observed. (Fig. 2). The recorded mean Tsk value in the neck area was lower than in the sternum area (TskNECK = $31.9 \pm 0.2^{\circ} \mathrm{C} ;$ TskSTERNUM $=32.5 \pm 0.1^{\circ} \mathrm{C}$ ). As a result of 15 minutes of selective cooling, a significant decrease of the skin surface temperature in the neck area was obtained at the level of $\triangle T$ TskNECK $=$ $-2.2 \pm 0.1^{\circ} \mathrm{C}$ and at the sternum surface $\triangle$ TskSTER$\mathrm{NUM}=-1.8 \pm 0.1^{\circ} \mathrm{C}$ (differences at the level of statistical significance of $p<0.01$ ).

\section{Thermal sensations and thermal comfort}

In the 30th minute of adaptation to the thermoneutral conditions, the participants assessed the local thermal sensations in relation to the neck and sternum surface and the state of thermal comfort in relation to the whole body as "pleasantly cool 3 " on average, which was in the range of thermal comfort (according to the Bedford Scale). No sig- nificant differences were observed between the sensitivity of the skin of the two analyzed areas of the neck and sternum.

Then, in the 30th minute of exposure to high temperature $\left(40^{\circ} \mathrm{C}\right)$, the participants assessed thermal sensations with respect to the neck and sternum area and thermal comfort with respect to the whole body as "too warm - 6" on average, which went beyond the range of thermal comfort (evoked a sense of discomfort according to the Bedford Scale). Again, no significant differences were found in relation to the areas of the neck and the sternum.

At high temperature $\left(40^{\circ} \mathrm{C}\right)$, combined with a 15-minute selective cooling stimulus on the neck, $70 \%$ of the participants felt an improvement in the subjective assessment of the state of thermal comfort in relation to the whole body ("pleasantly warm - 5", which was in the range of thermal comfort). In the case of cooling of the sternum area, a similar improvement was observed in $40 \%$ of the participants. The remaining participants in both series of experiments did not feel any change in the thermal state and still described it as "too warm - 6" (30\% of the participants using neck cooling, $60 \%$ of the participants using sternum cooling) (Fig. 3).

On the other hand, as a result of 15 minutes of local cooling in hot conditions, $80 \%$ of the participants described the thermal sensations in relation to cooling of the neck area as "pleasant - 4" and $50 \%$ of the participants gave the same assessment in relation to cooling of the sternum area. The other participants assessed the thermal sensation at an average level of "pleasantly warm - 5" (for the cooled neck area - 20\% of the participants, for the sternum - $50 \%$ of the participants). None of the participants assessed the thermal sensation

Skin temperature $[\Delta \mathrm{Tsk}]$

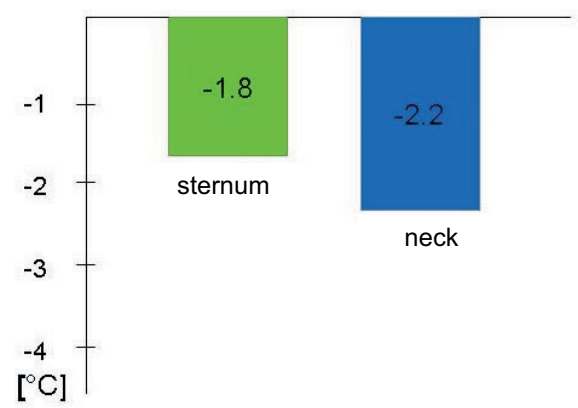

Fig. 2. Change of skin surface temperature $(\Delta T s k)$ as a result of 15 minutes of selective cooling of the neck and sternum in hot conditions $\left(40^{\circ} \mathrm{C}\right.$ ) (cooling surface: $100 \mathrm{~cm}^{2}$, stimulus temperature: $10-12^{\circ} \mathrm{C}$. 
as "too warm - 6" (baseline, in the climate chamber before the application of the "cooling pad"). Therefore, in hot conditions $\left(40^{\circ} \mathrm{C}\right)$ with 15 -minute cooling of selective areas of the body, a positive improvement in thermal sensations from "too warm - 6" to "pleasantly warm - 5" and "pleasant - 4" was observed in all participants. However, stronger sensations were observed in the cooled area of the neck than in the sternum, indicating a higher sensitivity of the skin in this area (Fig 4).

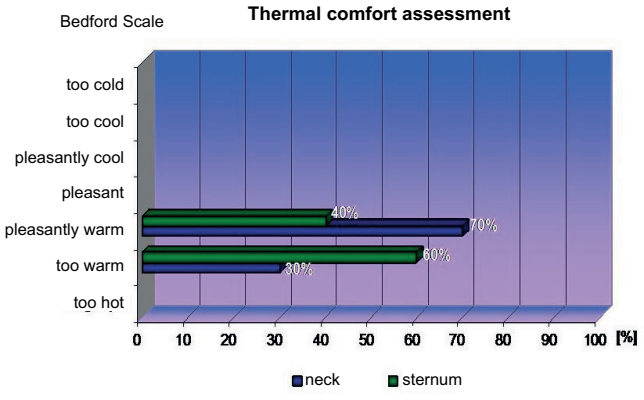

Fig. 3. Subjective assessment of thermal comfort after 15 minutes of selective neck and sternum cooling in hot conditions $\left(40^{\circ} \mathrm{C}\right)$, based on Bedford test.

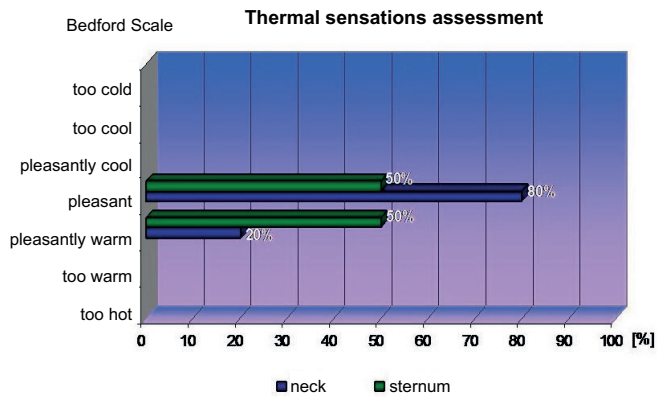

Fig. 4. Subjective assessment of thermal sensations obtained after 15 minutes of selective cooling, determined for the neck and sternum area at hot conditions $\left(40^{\circ} \mathrm{C}\right)$, based on Bedford test.

\section{DISCUSSION}

Maintaining a constant body temperature within a narrow range $\left(37 \pm 0.5^{\circ} \mathrm{C}\right)$ is crucial for existence because of the internal organs and their proper functioning. In warm-blooded organisms, the range of fluctuations in body temperature, under different environmental thermal conditions, is variable for different areas of the body (in limbs, these changes are clearly visible). It is extremely important to maintain an adequate internal tem- perature in the head area because of the brain, which is particularly sensitive to heat. Nervous tissue tolerates temperatures only up to about $40.5^{\circ} \mathrm{C}$, while organs located in the torso can tolerate internal temperatures of up to $42^{\circ} \mathrm{C}$. Therefore, from a physiological point of view, the temperature in the head and neck area is of great importance. Removing excess heat by cooling selected areas of the body can lower the increase of skin temperature, internal temperature and heart rate. By positively influencing the physiological reactions of the body, cognitive processes and satisfaction with the thermal environment are improved as a consequence, which translates into better performance when performing tasks.

In the studies carried out in simulated hot conditions $\left(40^{\circ} \mathrm{C}\right)$, body surface cooling of two body areas using the same thermal stimulus $\left(10-12^{\circ} \mathrm{C}\right)$ on the same area $\left(100 \mathrm{~cm}^{2}\right)$ and same duration (15 min) in hot conditions $\left(40^{\circ} \mathrm{C}\right)$ was performed. Unit tests consisted of the following: series I cooling of the neck area, series II - cooling of the sternum area. The aim of the study was to assess whether in these conditions the change of cooling location differentiates subjective thermal sensations and general thermal comfort of the body. In the scope of this issue, the change of local values of skin temperature (neck and sternum) and thermal sensations in relation to the selectively cooled surface and the state of thermal comfort determined in relation to the whole body were analyzed.

Prior to the application of a cooling stimulus, selected areas of the body were adapted to ambient temperature, first in a thermoneutral environment, and then to high temperature (simulated conditions of climate chamber). Then, in both cases, the local mean temperatures of the skin were similar. However, as a result of selective cooling in combination with exposure to high temperature $\left(40^{\circ} \mathrm{C}\right)$, various local changes in skin temperature $(\Delta \mathrm{Tsk})$ were observed in relation to cooled body surfaces (neck, sternum). In the neck area, the mean skin temperature decreased by $\triangle \mathrm{TskNECK}=-2.2 \pm 0.1^{\circ} \mathrm{C}$ and in the sternum area by $\triangle$ TskSTERNUM $=-1.8 \pm 0.1^{\circ} \mathrm{C}$ (Fig. 2). As a result of 15 minutes of cooling, the temperature of the skin surface in the neck area decreased more than in the sternum area. Thus, application of the cooling stimulus revealed a beneficial and significant decrease in skin temperature $(\Delta T s k)$ depending on the affected area (the place of application of the "cooling pad") (Fig. 2). The demonstrated significant changes in skin surface temperature in the analyzed body areas are a noticeable effect of thermoregulatory cooling probably caused by the ex- 
isting differences in tissue vascularization and skin blood flow in the examined body regions.

The contribution of core body temperature to the thermoregulation process is more significant than skin temperature (on average 10 times more significant for sweat secretion and 4 times more significant for shivering thermogenesis). However, in the perception of thermal sensations, skin and body temperature are of equal importance [5]. Within a small range of changes of this parameter (close to neutral), thermal sensations do not change and the body experiences thermal comfort. Whole body thermal comfort is a stage of thermoregulation that allows the body to maintain optimal activity. In case of thermal discomfort (including pain, e.g. due to excessive cooling), the body inhibits its activity in order to concentrate the thermoregulatory mechanisms on the possibility of restoring the state of comfort. Studies have shown that thermal sensations on skin surface depend on the size of the stimulated area and the temperature of the stimulus $[2,7,21]$.

In both series of selective body surface cooling (series I - neck, series II - sternum) a positive influence on the assessment of thermal state by the participants was shown. Under the heat conditions described above, thermal sensations were variable depending on the location of the cooled body surface. In the case of a low temperature stimulus in the neck area, the majority of participants (70\%) experienced an improvement in the subjective assessment of thermal comfort for the whole body from "too warm - 6" to "pleasantly warm - 5". However, during cooling of the sternum area, a comparable change in comfort assessment was observed only in $40 \%$ of the respondents. At the same time, the thermal sensations assessed in relation to the cooled body area improved from "too warm - 6" to "pleasant - 4". $80 \%$ of the respondents felt stronger cooling sensations from the neck area, and only 50\% from the sternum area (Fig. 3 and 4). Therefore, the improvement in the subjective assessment of the thermal conditions in relation to the whole body was clearly more pronounced after the application of selective cooling of the neck, rather than the sternum. The obtained results indicate an appropriate level of cooling, which could have contributed to the reduction of thermal stress levels in the body and at the same time did not cause the feeling of excessive cold and discomfort. Additionally, the aforementioned analysis of the change in skin temperature $[\Delta T s k]$ showed that the sensitivity of the body surface to low temperature stimuli in hot conditions is different in selectively cooled areas. On this basis, one might suggest that the neck area is more sensitive than the sternum. Therefore, the thermal sensations from the neck area have a greater effect on the overall thermal comfort of the body than the thermal sensations from the sternum area.

The above observations are consistent with the results of other studies. A team of scientists from the Waseda University of Tokyo lead by Mayumi Nakamura conducted an experiment in which four areas of the body (chest, abdomen, thigh, face) were heated and cooled [14]. Thermal sensations and thermal comfort were subject to analysis. It was observed that thermal comfort is dependent on the area in which the thermal factor was applied. In high temperature conditions $\left(32.5^{\circ} \mathrm{C}\right)$ causing a general feeling of discomfort, local cooling of the face surface with $25^{\circ} \mathrm{C}$ water resulted in an improvement in general thermal comfort, while heating the face area at $42^{\circ} \mathrm{C}$ deepened the discomfort in relation to the whole body. However, in moderately cool conditions, both heating and cooling of the surface of the face did not have a significant effect on the general thermal sensations [14]. In other studies, researchers from the UC Berkley observed that the feeling of cold in the head area, in hot conditions is perceived by humans as "pleasant" or even desirable, and what is more, it positively influences the thermal comfort in relation to the whole body [20]. Belding et al. were among the first to demonstrate that the skin temperature on the face has a significant impact on the mechanisms of thermoregulation of the human body [3,17]. A warm thermal stimulus to the face in a warm environment resulted in a much higher rate of sweating than when heating other body surfaces. Also, facial heating at a lower ambient temperature induced vasodilation, while the same heating of the chest surface (in terms of the surface and intensity of stimulus) or more distant areas of the body (feet) did not produce visible effects $[14,15,17]$.

It is possible that there is a special brain cooling system in humans, well known in animals (called "selective brain cooling"). Lowering the temperature of the head area (including the face, neck and neck) makes it possible to eliminate heat, the excess of which could contribute to brain tissue damage [11]. From a physiological point of view, the local action of the thermal factor (cold) may cause a local decrease in skin temperature (the effect of narrowing of small blood vessels in the skin), a change in thermal sensations from the body surface and thus positively influence the improvement of subjective impressions of the 
state of thermal comfort. Carrying out activities, maintaining physical activity and mental fitness in high temperature conditions with no cooling factors may cause excessive increase in the amount of heat accumulated in the body and, as a result, cause hyperthermia. Overheating poses a serious risk of impairing endurance and overall performance as a result of dehydration. A way to counteract and alleviate heat stress symptoms is to reduce the increase in thermal load through the implementation of favorable and efficient selective cooling systems. The method of selective cooling applied in the experiment proved to be helpful in alleviating thermal stress (which is evidenced by the improvement of mood, thermal comfort and thermal sensations). The sensed thermal stimuli were evaluated to varying degrees by the participants, depending on the selectively cooled parts of the body. In this respect, comparing the two analyzed areas, it can be concluded that under heat load caused by exposure to high temperature $\left(40^{\circ} \mathrm{C}\right)$, cooling of the neck region reduces the adverse changes in physiological reactions in the form of an increase in skin temperature compared to the cooled area of the sternum. Using cold stimuli indirectly counteracts the negative effects an overheating body of a soldier. It improves both subjectively perceived thermal sensations and overall thermal comfort. In this aspect, the method of selective cooling of the body surface may play an important role in expanding the limits of tolerance of the human system and have a significant impact on the quality and effectiveness of operations performed in the hot climate zone, which in modern military operations is a particularly demanding condition for their implementation.

\section{CONCLUSIONS}

Under thermal stress conditions, the psychophysical state of the body determines, to a large extent, the feeling of thermal comfort and fatigue level. The changes concerning subjective physiological and psychological indicators analyzed in the paper confirm that:

1. When used as a selective cooling method in hot conditions $\left(40^{\circ} \mathrm{C}\right)$, the local sensitivity of the skin to low temperatures is greater in the neck area than in the sternum area.

2. Selective cooling of the neck surface significantly improves the thermal sensation in relation to the cooled area of the body $(80 \%$ of the participants evaluated their own thermal sensations in the neck area as "pleasant"- 4).

3. Selective cooling of the skin in the sternum area applied in hot conditions also improves thermal sensations determined in relation to the cooled body location (50\% of the participants assessed the thermal sensations as "pleasant" - 4).

4. The improvement in the subjective assessment of thermal comfort in relation to the whole body was clearly more pronounced after the application of selective cooling on the neck surface compared to the cooled area of the sternum (in the case of the neck - 70\% of the respondents, the sternum - $40 \%$ of the respondents assessed the comfort as "pleasantly warm" - 5).

5. Local cooling of the neck and sternum surface at a high temperature $\left(40^{\circ} \mathrm{C}\right)$ with a low temperature stimulus $\left(10-12^{\circ} \mathrm{C}\right)$ does not cause thermal discomfort (feeling of excessive cold).

\section{AUTHORS' DECLARATION:}

Study Design: Anna Przewodzka, Anna Czerwińska; Data Collection: Anna Przewodzka, Anna Czerwińska; Manuscript Preparation: Anna Przewodzka, Anna Czerwińska; Funds Collection: Anna Przewodzka, Anna Czerwińska. The Authors declare that there is no conflict of interest. 


\section{REFERENCES}

1. Arens $\mathrm{E}$, Zhang $\mathrm{H}$, Huizenga C. Partial- and whole-body thermal sensation and comfort, Part II: non-uniform environmental conditions. J Therm Biol. 2006; 31(1-2):60-66.

2. Arens E, Zhang H, Pan N, Gibson P. The Skin's Role in Human Thermoregulation and Comfort. Thermal and Moisture Transport in Fibrous Materials, Woodhead Publishing Ltd. 2006; 560-602.

3. Belding HS, Macht MB, Bader ME. Indirect peripheral vasodilation produced by the warming of various body areas. US Army Quartermaster Research Develop Center, Natick, Massacussetts Environmental Protection Report. Natick, MA: US Army. 1948; 132.

4. Desruelle AV, Candas V. Thermoregulatory effects of three different types of head cooling in humans during a mild hyperthermia. Eur J Appl Physiol. 2000; 81:33-39.

5. Frank SM, Raja SN, Bulcao CF, Goldstein DS, Relative contribution of core and cutaneous temperatures to thermal comfort and autonomic responses in humans. J Appl Physiol. 1999; 86(5):1588-1593.

6. Gao C, Kuklane K, Wang F, Holmér I. Personal cooling with phase change materials to improve thermal comfort from a heat wave perspective. Indoor Air. 2012; 22:523-530.

7. Hensel H. Thermoreception and Temperature Regulation. Academic Press London and New York, 1981.

8. Kräuchi K. The human sleep-wake cycle reconsidered from a thermoregulatory point of view. Physiol Behav. 2007; 90:236-245.

9. Lan L, Qian XL, Lian ZW, Lin YB. Local body cooling to improve sleep quality and thermal comfort in a hot environment. Indoor Air. 2018; 28:135-145.

10. Lee JKW, Kenefick RW, Cheuvront SN. Novel cooling strategies for military training and operations. J Strength Cond Res. 2015; 29 (11S):77-81.

11. Matsuda-Nakamura M, Wada S, Marui S, Sata N, Nagashima K. The effect of head or neck cooling on body core temperature and thermal sensation in humans. Faseb Journal. 2014; 28:1supplement.

12. McEntire SJ, Suyama J, Hostler D. Mitigation and prevention of exertional heat stress in firefighters: a review of cooling strategies for structural firefighting and hazardous materials responders. Prehosp Emerg Care. 2013; 17(2):241-60.

13. Miyata S, Noda A, Iwamoto K, Kawano N, Okuda M, Ozaki N. Poor sleep quality impairs cognitive performance in older adults. J Sleep Res. 2013; 10:35 PM-41.

14. Nakamura M, Yoda T, Crawshaw L. Regional differences in temperature sensation and thermal comfort in humans. J Appl Physiol. 2008; 105(6):1897-1906.

15. Nakamura M, Yoda T, Crawshaw LI. Relative importance of different surface regions for thermal comfort in humans. Eur J Appl Physiol. 2013; 113:63-76.

16. Nunneley SA, Reader DC, Maldonado RJ. Head-temperature effects on physiology, comfort, and performance during hyperthermia. Aviat Space Environ Med. 1982; 53(7): 623-628.

17. Pallubinsky H, Schellen L, Rieswijk TA. Local cooling in a warm environment. Energy Build. 2016; 113:15-22.

18. Someren EJW. Mechanism and functions of coupling between sleep and temperature rhythms. Prog Brain Res. 2006; 153:309-324.

19. Telzer EH, Fuligni AJ, Lieberman M, Galván A. The effects of poor quality sleep on brain function and risk taking in adolescence. Neurolmage. 2013; 71:275-283.

20. Zhang H. Human Thermal Sensation and Comfort in Transient and Non-Uniform Thermal Environments. Ph. D. thesis. Center for the Built Environment, University of California, Berkeley 2003.

21. Zhang $\mathrm{H}$, Arens $\mathrm{E}$, Huizenga $\mathrm{C}$, Han T. Thermal sensation and comfort models for non-uniform and transient environments: Part III: Whole-body sensation and comfort. Center for the Built Environment, University of California, Berkeley 2009.

Cite this article as: Przewodzka A, Czerwińska A. Effects of Selective Cooling of Specific Human Body Surface Areas on Subjective Assessment of Thermal Comfort in Hot Conditions. Pol J Aviat Med Bioeng Psychol 2018; 24(1): 5-13. DOI: 10.13174/ pjambp.06.08.2019.01 